medication. The magnitude of the decline in performance from the immediate to the delayed paradigm was linked to the size of the hippocampi at time of testing. One year later, the prolonged febrile seizure group still showed impairments in remembering a face after a 5 min delay. Age at the time of the seizure was not a factor. (Martinos MM, Yoong M, Patil S, et al. Recognition memory is impaired in children after prolonged febrile seizures. Brain 2012 Oct;135(Pt 10):3153-64). (Respond: Rod C Scott PhD, Dartmouth Medical School, Lebanon, NH. E-Mail: Rodney.C.Scott@Dartmouth.edu).

COMMENT. In this study concerning the effects of prolonged febrile seizures on recognition memory, a visual paired comparison task employing faces was used to test memory abilities in small infants. Prosopagnosia, an inability to recognize faces, is congenital and genetic or acquired. The congenital form may be inherited by $\sim 2.5 \%$ of the population. The brain region associated with prosopagnosia is usually stated as the fusiform gyrus or an occipito-temporal location, contiguous with the hippocampal gyrus, the location emphasized in the above study. Congenital prosopagnosia is not rare. Oliver Sacks himself confused the faces of his brothers and learned that his relatives were similarly affected (Sacks O. A Neurologist's Notebook: Face-blind. Why are some of us terrible at recognizing faces? The New Yorker 2010 Aug 30:36). A PubMed search of the literature uncovered reports of significant improvements in familiar face recognition following training of a 4-year-old child with congenital prosopagnosia (Schmalzl L, et al. Cogn Neuropsychol 2008 Jul;25(5):704-29). Training focused on directing visual attention to specific characteristics of the face, particularly the eye region. The performance became flawless immediately after training as well as at a follow-up assessment 1 month later. Since the visual paired comparison task uses the face in repetitive tests of memory, practice effects on an inherent prosopagnosia are a possible modifying factor in studies of the effect of prolonged febrile seizure on face recognition and memory in infants.

\title{
ATYPICAL FACE SHAPE AND GENOMIC VARIANTS IN EPILEPSY
}

Researchers at the Institute of Neurology, Queen Square, London; Children's Hospital, Florence, Italy; and other centers in the UK, Belgium, and the Netherlands studied face shape abnormalities in 118 children and adults attending three European epilepsy clinics, using an objective measure called Face Shape Difference to show that those with pathogenic structural variants have a significantly atypical face shape. In a second group of 63 patients the predictive accuracy of the measure showed high sensitivity ( $80 \%$ for whole face, $60 \%$ for periorbital and perinasal regions) and specificity (78\% for whole face and perinasal regions, $69 \%$ for periorbital region). Computer-based stereophotogrammetry and dense surface models were effective in detecting subtle relevant face shape abnormalities or dysmorphisms in patients with epilepsy and pathogenic structural genomic variants, as determined by chromosome microarray. (Chinthapalli K, Bartolini E, Novy J, et al. Atypical face shape and genomic structural variants in epilepsy. Brain 2012 Oct;135(Pt 10):3101-14). (Respond: Dr Sanjay M Sisodiya, Department of Clinical and Experimental Epilepsy, UCL Institute of Neurology, Queen Square, London WC1N 3BG, UK, E-mail: s.sisodiya@ucl.ac.uk). 
COMMENT. Patients with epilepsy and pathogenic structural genomic microarray variants have an objectively more atypical face shape compared with those without. The authors suggest that an evaluation for facial dysmorphism should be part of the clinical work-up for epilepsy. The concept of a "facies epileptica" as defined by Turner (Turner WA. Epilepsy: A Study of the Idiopathic Disease. London: Macmillan and Co; 1907.), is now regarded as unacceptable. Given the heterogeneity of epilepsy, 3D stereophotogrammetry and dense surface models are not expected to identify a specific "face" associated with epilepsy, and actual facial shapes are as varied as the underlying pathogenic structural variants. An objective measure of face shape variation might be used in clinical selection of patients with epilepsy who should be considered for microarray chromosome analysis.

\section{GENETIC NEUROLOGICAL SYNDROMES}

\section{EPILEPSY IN MUENKE SYNDROME}

Researchers at the National Institutes of Health, Bethesda, MD; Children's National Medical Center; and George Washington University, Washington, DC present 7 patients with Muenke syndrome complicated by epilepsy. A review of 789 published cases of Muenke syndrome with neurological complications identified epilepsy in 6 cases, with intracranial anomalies in 5. The intracranial anomalies were agenesis of the corpus callosum, hemimegalencephaly, and porencephaly. In the review of 58 patients with Muenke syndrome in the Washington, DC cohort, 7 (12\%) had epilepsy and 4 survived neonatal apnea. Patients with Muenke syndrome should be monitored for apnea and seizures. Those with seizures or febrile seizures should undergo neuroimaging, preferably MRI. (Agochukwu NB, Solomon BD, Gropman AL, Muenke M. Epilepsy in Muenke syndrome: FGFR3-related craniosynostosis. Pediatr Neurol 2012 Nov;47(5):355-61). (Respond: Dr Muenke, Medical Genetics Branch, National Human Genome Research Institute, National Institutes of Health, Bldg 35, Bethesda, MD 20892. E-mail: mamuenke@mail.nih.gov).

COMMENT. Muenke syndrome has an autosomal dominant inheritance and is characterized by craniosynostosis, most commonly coronal uni- or bilateral, asymmetry of skull and face, sensorineural hearing loss, developmental delay, broad toes and thumbs, fusion of carpal and tarsal bones, hypertelorism, ptosis, strabismus, midface hypoplasia, and fronto-temporal bossing. The syndrome is caused by a mutation in the FGFR3 gene, with variable expressivity and phenotype. (Doherty ES, et al. Muenke syndrome (FGFR3-related craniosynostosis): expansion of the phenotype and review of the literature. Am J Med Genet A 2007 Dec 15;143A(24):3204-15). Other craniosynostosis syndromes associated with the fibroblast growth factor receptors (FGFR) include Crouzon, Apert, and Pfeiffer syndrome. (Millichap JG. Neurological Syndromes. A Compendium for Clinicians. New York: Springer; 2013. In press). 